Article

\title{
Coordination of Digital Transformation in International Manufacturing Networks-Challenges and Coping Mechanisms from an Organizational Perspective
}

\author{
Viktorija Badasjane*, Anna Granlund (D, Mats Ahlskog and Jessica Bruch \\ Division of Product Realization, School of Innovation, Design and Engineering, Mälardalen University, \\ SE-632 17 Eskilstuna, Sweden; anna.granlund@mdh.se (A.G.); mats.ahlskog@mdh.se (M.A.); \\ jessica.bruch@mdh.se (J.B.) \\ * Correspondence: viktorija.badasjane@mdh.se; Tel.: +46-1615-5137
}

check for

updates

Citation: Badasjane, V.; Granlund, A.; Ahlskog, M.; Bruch, J. Coordination of Digital Transformation in International Manufacturing Networks-Challenges and Coping Mechanisms from an Organizational Perspective. Sustainability 2022, 14 , 2204. https://doi.org/10.3390/ su14042204

Academic Editors: Julian Müller and Nicola Saccani

Received: 26 November 2021

Accepted: 11 February 2022

Published: 15 February 2022

Publisher's Note: MDPI stays neutral with regard to jurisdictional claims in published maps and institutional affiliations.

Copyright: (C) 2022 by the authors. Licensee MDPI, Basel, Switzerland. This article is an open access article distributed under the terms and conditions of the Creative Commons Attribution (CC BY) license (https:// creativecommons.org/licenses/by/ $4.0 /)$.

\begin{abstract}
Coordinating the digital transformation of globally dispersed factories within international manufacturing networks has become a critical issue for competitiveness, yet there has been limited attention paid to this issue in previous research. Therefore, the purpose of this paper is to, from an organizational perspective, explore the challenges in coordinating the digital transformation in an international manufacturing network and the coping mechanisms to overcome those challenges. A case study is conducted in a manufacturing company within the heavy vehicle industry, thus contributing to the limited empirical research covering coordination of digital transformation. The data is analyzed through organizational structure and design theory, and the findings are mapped into four core dimensions: differentiation, integration, centralization, and formalization. The results show 15 challenges and 11 coping mechanisms for coordination of digital transformation in international manufacturing networks, identifying the significance of the coordination uncertainty within the formalization dimension that is particularly exposed to the changes induced by digital transformation. The findings include the need for a coordination-oriented organizational structure that incorporates how and where coordination can be actualized. The research implications contribute with new insights by providing a detailed description of the created organizational structure and, in contrast to previous research, focuses specifically on the coordination aspect of digital transformation in an international manufacturing network.
\end{abstract}

Keywords: global production; digitalization; organizational structure and design theory; organizational structure; digital technologies; manufacturing networks; collaboration; operations management

\section{Introduction}

Coordinating globally dispersed factories belonging to an international manufacturing network (IMN) can be a source of competitiveness [1]. The fundamental idea of coordinating IMNs is to create a competitive advantage by pooling resources, spreading knowledge about technology and processes, and synchronizing the distributed development activities within the IMN [2]. However, the coordination of IMN is complex from a strategic and an organizational perspective. Decisions must be made regarding where development activities should be performed and how the developed knowledge should be spread within the IMN [3]. Hence, coordination comes with complexity, and organizational factors are more intricate in IMNs, where new technology implementation, processes, and management innovations have more dependencies and coordination challenges [4].

Simultaneously, the complexity of coordination of IMNs is further increased as the manufacturing industry is undergoing a digital transformation [5]. For global companies, the digital transformation is a fundamental change and long-term engagement that reaches beyond digital technologies and the digitalization of factories [6]. Digital transformation is especially a challenge without a uniform solution, rules, or outcome that can simply 
be applied by a company [7]; it cannot be seen as digital technology implementation because digital transformation requires a holistic approach rather than a limited view on single technologies [8].

Nevertheless, digital transformation is responsible for driving development and economic growth and adds to competitiveness and business efficiency as digital technologies combined with globalization enable a global digital ecosystem [9]. Digitalization has become one of the main focuses for manufacturing companies to address the sustainability of production, machines, and processes [10]. Specifically, technology is seen as a fundamental enabler that can support the strive for sustainable manufacturing. The economic, environmental, and social objectives can be satisfied by using new technology to influence and interact with sustainability's three pillars [11]. For instance, information and communication technologies have been applied for addressing societal issues, such as housing and climate change [12]. Hence, digital technologies provide novel opportunities for different sectors and businesses [13]. However, digital technologies, accompanied by increasing digital competition and resulting digital customer behavior, lead to changes that trigger digital transformation and set demands on firms' digital resources, organizational structure, and growth strategies and metrics. Hence, digital transformation requires both acquiring digital assets and developing capabilities, such as digital agility [14].

In contrast to other transformations, digital technologies have accelerated the speed of change, further causing increased complexity and uncertainty [15], and that digitalization will continue to change working processes at companies [16]. This induces more pressure on IMNs to pool their resources and develop new or adjust their current ways of coordinating the IMN to realize the desired competitive advantage. A key challenge for IMNs is developing an organizational structure that can support the coordination of a digital transformation [4,17]. For example, Deflorin et al. [18] pointed out that coordination needs to be adapted to support the implementation of digital technologies across the IMN. In general, digital transformation has been studied from different perspectives ranging from digital technology implementation [18], strategy for digital transformation [19], or highlighting factors contributing to or hindering a digital transformation on a more general level [17]. Researchers have investigated global value chains, e.g., how digital technologies influence or affect the location and organization of activities [20] or the design of ecosystems where decentralization of activities and new organizational forms have been observed [21]. Also, changes, such as organizational decentralization, have been linked to improved integration and efficiency within value chains and manufacturing networks [22,23]

However, the majority of current research focuses on digital technology enablers [24]. While the digital transformation brings about changes to the organizational structure $[4,14,17,25]$, to our knowledge, the organizational structure specifically for coordinating digital transformation across IMNs has not been the focus of recent research. Therefore, the purpose of this paper is to, from an organizational perspective, explore the challenges in coordinating the digital transformation in an IMN and the coping mechanisms to overcome those challenges. The expected results are to, through a case study, provide empirical evidence exemplifying how an IMN organizes for digital transformation, identify and through contextual descriptions describe experienced challenges with the coordination of digital transformation in IMNs, and possible coping mechanisms to overcome these. Thus, a better understanding of, from an organizational perspective, the coordination of digital transformation in IMNs, can be approached.

Contributions of the paper. This study makes three distinct contributions to the literature by positioning digital transformation within the context of coordination of IMNs and examining it from an organizational perspective.

First, an organizational perspective is adopted by drawing from the organizational structure and design theory. Hence, a better understanding of the evolution of digital transformation at the organizational level is achieved [26]. Research covering how companies can create an organizational structure to succeed in digital transformation is urged, including contextual descriptions to provide a better understanding [14]. This study answers 
this call, and a detailed description of the organizational structure created to coordinate digital transformation in an IMN is provided in this paper. Also, where previous research has investigated possible organizational structures for digital transformation, e.g., crossfunctional teams [17,27], the emphasis in this study is specifically on the coordination within the described organizational structure.

The second contribution is that the coordination of the digital transformation is examined from an IMN view, thus complementing prior factory-focused research on digital transformation. The IMN view implies the need for coordination between factories; however, challenges and coping mechanisms specifically with the coordination of digital transformation at the IMN level have been unknown. This paper identifies 15 challenges and 11 actual or possible coping mechanisms that add to the body of literature on the coordination of IMNs.

Third, empirical research in the operations management field of global operations was urged by Ferdows [5], as such research is currently limited. Likewise, empirical research covering digital transformation is limited [4]. Even though digital transformation has numerous implications for the organizational structure, empirical research is also limited in this area [14]. This paper adopts a qualitative case study approach to provide concrete industry examples from a manufacturing company. This contribution can increase the knowledge for practitioners who aim to explore the possibilities with coordination of digital transformation and avoid the pitfalls. Hence, this study answers the call for intentionally focusing on applied research that is useful within the manufacturing sector [28].

Structure of the paper. The remainder of the paper is structured as follows. First, the theoretical background introduces previous research in the areas of coordination of IMNs, digital transformation, and organizational structure for coordination of digital transformation in IMNs. Then the research design is described, followed by a presentation of the empirical results. Further, the results are discussed together with their implications, and finally, the conclusions are summarized.

\section{Theoretical Background}

\subsection{Coordination of International Manufacturing Networks}

In an IMN, coordination links the factories by establishing physical and non-physical flows between them, facilitating collaboration and synchronization [29,30], and providing advantages, such as the opportunity for increased knowledge about technology and processes across the IMN [31]. Coordination is a prerequisite for integrating management skills, product or process development, and knowledge within the IMN [29,30,32]. Also, best practices need to be coordinated, which can concern production engineering and technology, production processes and systems, and administrative processes and systems [33]. Coordination is thus an important means to strengthen the overall performance of the IMN [34].

Engaging employees from each factory can create a joint base of best practices, joint innovation, and local responsiveness to individual factory needs [33,35]. Activities that involve the transfer of managers, communication within factories, and training and development programs are referred to as informal coordination. Informal coordination has the outcome of an organizational culture that shares objectives [36]. Establishing competence groups on an IMN level can be the driving force for continuous improvement of the operations strategy and collaboration. This group represents the experience from individual factories and insights into factories' needs. Thus, it balances global strategic plans and roadmaps with local responsiveness regarding ideas and needs [33].

Each factory requires unique adjustments in coordination to fit their needs [37]. Because the decisions made in one factory can affect the rest of the IMN [32], coordination involves the identification and classification of interdependencies; as they differ, the coordination processes must be adjusted accordingly [3]. The factories should continuously partake in newly developed technology by receiving knowledge, development, and product and process updates and improvements [33]. Keeping track of development activities across the IMN promotes insight and understanding of the factories' prerequisites and 
requirements. More precisely, because factories differ in experience, competence, resources, and technology maturity, the extent and type of needed support varies. Usually, support is person-dependent, performed ad-hoc, and may require face-to-face assistance regarding short- and long-term initiatives. The absence of formal structures, such as processes, routines, and structures, can confuse coordination performance, such as providing support [38]. Also, the likelihood of a factory sharing information within the IMN is small without first establishing internal systems and communication channels across functional borders [29]. Hence, formal management structures are essential to facilitating coordination and cover decision-making rights and responsibilities [32,39]. Formalization also includes written policies, rules, job descriptions, and procedures [36]. Moreover, the collaboration between factories does not happen organically; instead, it needs a detailed plan [38] to remove functional silos across factories in an IMN [40]. Also, close collaboration with corporate and local management [33] and participation in decision-making [41] are pinpointed as a means to coordinate.

\subsection{Digital Transformation}

Digital transformation is an overarching concept encompassing the digitalization of production using digital technologies [4,42]. Previous research uses the terms digitalization and digital transformation interchangeably. However, Gong and Ribiere [43] describe that digitalization is mainly focused on work at the operational level, whereas digital transformation emphasizes results at the strategic level. Moreover, digitalization entails the exploration of digital technologies (e.g., IIoT, AI, cloud computing) and their combination [44-46]. Overall, digitalization has the potential to increase productivity [47] and sustainability of production [10], as digital technologies can impact sustainable manufacturing elements at the product, process, and system levels [48]. For instance, Enyoghasi and Badurdeen [49] have compiled how different digital technologies enable economy (i.e., manufacturing cost), environment (i.e., energy consumption, waste management, environmental impact), and society (i.e., personal health, operator safety). Specifically, enhancing decision-making and enabling process monitoring and predictive maintenance by the use of IIoT [50,51] can lead to multiple improvements, such as to personal health and safety (i.e., society) [52] and reduced machine downtime and decreased material cost (i.e., economy) [52,53].

In comparison, Vial [26] discusses that the meaning of digital transformation relates to organizations and the nature of the transformation taking place. Digital transformation means a fundamental change in the ways of working or thinking, thereby affecting culture, strategies, product and process improvements, managerial aspects, and organizational structures $[43,54,55]$. Thus, companies undergo a transformation that transcends functional thinking and includes viewing actions from a holistic perspective $[55,56]$. The challenges posed by the disruption of digital technologies can thus be diminished when they are viewed as organizational and managerial problems [7].

\subsubsection{Challenges with and Coping Mechanisms for Digital Transformation}

The challenges of digital transformation can, for instance, be a lack of standards for technology and processes and the willingness to collaborate across the network, causing issues for implementing and integrating digital technologies. Also, a challenge is posed when leadership does not possess the needed digital transformation skills, competence, and experience required. Specifically, the ability to balance the local and network levels is essential [4]. Consequently, new governance structures that include vital stakeholders and the organizational and managerial processes need to be formed [17].

However, viewing the digital transformation from a long-term perspective can ease coping with mistakes and view them as learning opportunities [27]. Likewise, communication campaigns can support digital transformation, preventing the lack of common thinking and the organization's otherwise contradictory interests $[4,17]$. Similarly, top management's conviction, involvement, and support are necessary [17]. 
Because a lack of conscious planning, including needed resources, can pose a challenge, strategic digital transformation management needs to be established to define strategies, vision, and corresponding actions [4,57]. The appointment of a cross-functional team with the overall responsibility for the digital transformation is one way forward [27]. This sort of team can have multiple functions. They can act as a bridge between functions and therefore possess a vital role in coordinating technological and organizational innovations [17]. At the same time, a similar team needs to perform the everyday digitalization activities and synchronize them with the overarching transformation process [27].

\subsubsection{Organizational Structure for Coordination of Digital Transformation in IMNs}

Digital transformation implies significant changes not only to the technology but to the organizational structures, making it a challenging endeavor to undertake, especially for large companies $[4,6,17,19,54]$. Digital transformation contains complexities and uncertainties, e.g., the involvement of many organizationally dispersed stakeholders and interdependencies. Therefore, it is challenging to grasp the consequences of any action made in the organization $[15,27]$. Essentially, as digital transformation is highly complex and associated with uncertainty, the chosen organizational structure may need to be adapted continuously due to a rapidly changing environment, requiring organizational flexibility and openness to change [4,27].

Hence, the importance of organizational structures is particularly relevant in the digital transformation area, especially in IMNs, where coordination should link the factories and facilitate collaboration and synchronization. Therefore, this study applies the theoretical perspective of organizational structure and design theory [58] to study the coordination of digital transformation in IMNs. Specifically, this theory contains four core dimensions of differentiation, integration, centralization, and formalization [58], which are used. The core dimensions are fundamental constituents of every organizational structure [58] and have been used in previous research to study, for instance, organizations' creation of dynamic capabilities [59] and have been shown to capture changes in organizational structure and level of coordination [60]. Of the core dimensions, differentiation refers to how far an organization, such as an IMN, is broken down into numerous parts and the degree of deviation among the various parts [61]. Differentiation covers the division of labor among the employees or teams, creating specialized individuals or teams that can spend their limited resources on their area of specialization [62]. Further, they can identify potential misalignments of action and resources and make adjustments [63]. Moreover, temporary or permanent cross-functional teams of managers across different parts of the organization can facilitate coordination [64]. Integration is related to how well the parts of an organization are coordinated [65], for example, the different parts of an organization must share information [64]. This, however, requires systems or mechanisms for linking the parts together to be put into place $[59,65]$. Centralization refers to where decisions are made in an organization. High centralization implies that control is mainly performed through top management, while low centralization implies higher autonomy for middle-level and lower-level employees and relies on their expertise and initiatives [61]. Lastly, formalization refers to the standardization of work processes and documentation. Formalization is used as a mechanism for coordination, including rules and procedures [61]. Hence, an alignment can be identified between the content of the core dimensions and the previous research covering the constituents of coordination. Using the core dimensions can thus permit uncovering changes to the organizational structure induced by digital transformation and explain the corresponding coordination thereof.

\section{Research Design}

A case study was carried out to comply with this paper's purpose: from an organizational perspective, explore the challenges in coordinating the digital transformation in an IMN and the coping mechanisms to overcome those challenges. An empirical data collection approach was motivated by the limited empirical research covering coordination 
of digital transformation [4]. The strength of analyzing qualitative data is that it illuminates the local context, understands latent or underlying subjects, and reveals complexity [66], which corresponds to the purpose of this study. According to Ferdows [5], researching global operations is associated with difficulty, as it contains a high level of detailed and dynamic complexity and hysteresis. Hence, the traditional research methodologies in operations management (OM) need to expand to include, e.g., case-based research. The case study method has been applied in recent research to, for instance, uncover IIoT enablers to manufacturing coordination mechanisms [18] or competing and interrelated concerns when embracing digital innovations in incumbent firms [67]. Moreover, in a systematic literature review, Loonam et al. [15] found 10 case studies covering the successful implementation of digital technologies in organizations. Hence, the case study method specifically is an appropriate choice to understand a multifaceted and context-bound phenomenon, such as the coordination of digital transformation. It also promotes obtaining new and creative insights and has high validity for practitioners [68], which is important in this contemporary research area. The case study approach is suitable when, as in this research, aiming at theory building due to the likelihood of generating novel theory from cases $[68,69]$. As limited research has offered explanations for executing the coordination of digital transformation in a real-life setting, the case study method was, despite its limitations in generalizability, deemed most suitable to begin to fill the identified research gap. This, as it enables in-depth studies of complex phenomena [70], is in contrast to other methods, such as surveys, which can provide a broader reach but have limited depth.

Figure 1 illustrates the application of the case study method in this study. The overall methodology was iterative, and the process can be summarized into three major phases: conceptualization, data collection, and data analysis. The content in the three phases in Figure 1 is based on key steps proposed by Yin [70], Voss [71], and Miles and Huberman [66].

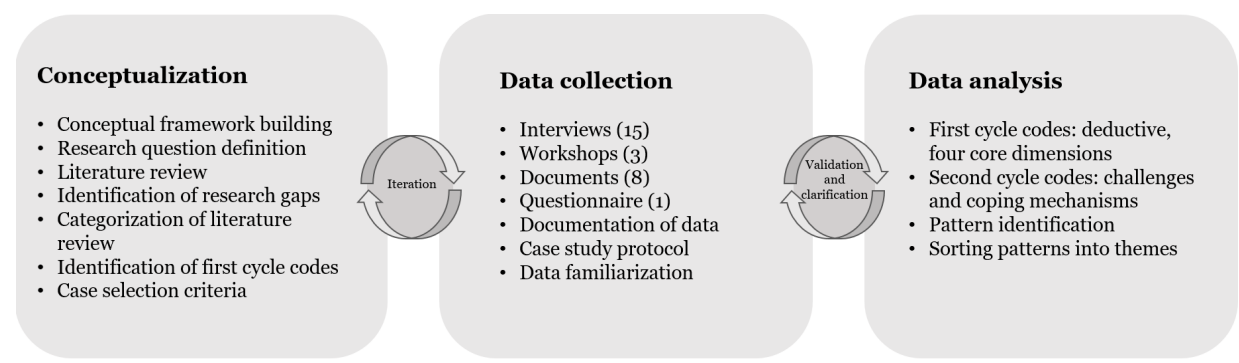

Figure 1. Overview of case study application, based on key steps proposed by Yin [70], Voss [71], and Miles and Huberman [66].

A conceptual framework was formulated in line with Voss [71] that included the main areas to be studied (i.e., coordination of digital transformation within the context of IMNs, the organizational structure for digital transformation, challenges, and coping mechanisms) and the relationships among the main areas. This was complemented by a literature review and identifying research gaps in previous research [70]. Also, the conceptual framework was accompanied by developing the preliminary research question [71] that could guide data collection and case study planning [70]. Moreover, as the purpose was studied from an organizational perspective, the conceptualization included identifying first cycle codes for the data analysis.

The reasoning behind the case selection was twofold. First, the company had to operate an IMN, which in itself requires coordination. Second, great emphasis was placed on selecting a company that actively works with coordinating digital transformation in its IMN. This meant, for instance, the ways of working, organizational changes, and developing digital transformation strategy for the IMN. The intent was to follow an IMN during the evolution of digital transformation and the development of organizational structures. Hence, the case selection was in line with Patton [72] to select a case with a richness of examples about the studied phenomenon and that the case can be considered a reasonably common representation, 
i.e., without extreme examples of success or failure. The identified research gaps and research question were discussed with the selected case company, implying that a common problem between the case company and researchers was identified.

Further, the case study method allows different data collection techniques and sourcing, supporting the ability to gather a rich set of data by, e.g., observations, interviews, and documents [68], further supporting the chosen method over other available methods using single data collection techniques. This study used triangulation of data collection techniques to increase validity, i.e., interviews, workshops, documents, and a survey. The data analysis consisted of several steps, starting with the analysis using the first cycle codes, identifying second cycle codes of challenges and coping mechanisms, and identifying patterns among them that led to sorting the patterns into themes. Data collection and analysis are further described in the upcoming sections.

\subsection{Data Collection}

A manufacturing company within a heavy vehicle industry was selected for this study. The selected manufacturing company has production factories in the Americas, Europe, and Asia. The case company has approximately 15 thousand employees, is represented in 180 countries, and is one of the leading five Original Equipment Manufacturers (OEMs) worldwide. The selected case company had established a global team responsible for coordinating the digital transformation of the IMN in 2018. During 2019, local teams with the operational responsibility of digitalization in each of the company's 14 factories were established.

Data collection took place between December 2019 to June 2021 through 15 semistructured interviews with 15 respondents, 3 workshops, 1 questionnaire, and various company documents. The interview respondent's position covered both strategic and operational perspectives, and the respondents were located in different factories or global organizations in Europe and Asia. The data sample mainly included global team members (14 out of the 15). Out of those, 10 of the respondents were either global managers or specialists with a global responsibility (referred to as global team member 1, 2, 3 etc. in the following text) with diverse competence areas, such as IT, logistics, manufacturing engineering, quality and data management, $\mathrm{HR}$, virtual manufacturing, and sustainability.

Four of the global team members were also local team members or leaders, with different competence areas, such as maintenance, IT, application engineering, and manufacturing development. This implies that they had dual roles by representing both the global team and a local team at a factory. The global team leader was a global manufacturing engineering manager who reported directly up to top management. Top management here includes, for instance, the manufacturing engineering vice president for the IMN located in the company's global organization. Also, one local team leader that was not part of the global team was included in the sample to strengthen the understanding of digital transformation on the factory level.

Each interview lasted between 45-60 min. The interview guide focused on three main areas. The first segment of interview questions was about the organizational structure created for the digital transformation (e.g., its constituents, vision, goals, ways of working). These questions aimed to map the organizational structure for digital transformation, emphasizing the underlying reasons for and the effect of this particular structure. Also, to identify the differences between the general organizational structure and the novelty of the one created for digital transformation. In the second segment of interview questions, the execution of coordination within the organizational structure for digital transformation was examined (e.g., what needs to be coordinated, how is it performed and why in this way, example of coordination activities, how does coordination of digital transformation differ from usual IMN coordination). The last question segment focused on challenges and coping mechanisms (e.g., identifying activities or aspects of coordination of digital transformation that are perceived as challenging, understanding when a challenge is present, possible causes, how the challenge is handled, how the organizational structure affects or supports coping with the challenge). 
The semi-structured interviews were followed up with 3 workshops with representatives from the case company (varied from 2-6 respondents) and 3-4 researchers. The workshops lasted for approximately three hours each and had different topics for discussion. The first workshop was held to gain insight into the overall challenges of digital transformation in the IMN to understand the case company's context and provide an overview of challenges. A questionnaire was sent out before the second workshop that had four respondents and covered challenges with digital transformation on an overview level. During the second workshop, the compiled results of the questionnaire were presented and discussed. The third workshop focused on obtaining a more detailed overview of both the challenges and coping mechanisms for the coordination of digital transformation.

The interviews and the workshops were performed digitally and were audio and video recorded to ensure that the documents and information shared were kept for review. The interviews were also transcribed. A continuous dialogue with a key representative at the case company was held during the entire study to validate findings or clarify questions. Also, documents complemented the data collection. The majority of the collected documents were official company information that described either the company's organizational structure or the digital transformation principles. These increased the contextual understanding of the company and benefitted triangulation [69]. The researchers' role in this study was to describe how the results were reached and critically review the research process while the case company shared organizational experience, best practices, and methods.

\subsection{Data Analysis}

Data analysis was an iterative process between collected empirical data and theory to draw transparent conclusions. First, the literature reviewed was stored and categorized, and the key findings from the literature were derived and stored in a database which enabled the identification of research gaps and the development criterion for case company selection. The literature review was ongoing during the data collection and data analysis phases.

Collected empirical data was documented and coded using NVivo. A case study protocol was used to filter the data and arrange occurrences in chronological order [70]. The transcribed interviews were re-read on multiple occasions to gain familiarity with the data. Moreover, the data collection and analysis were performed iteratively and consisted of cycles of identifying data gaps and the collection of enriching data [66].

The collected data were analyzed using the four core dimensions of differentiation, integration, centralization, and formalization, which are the fundamental constituents of the organizational structure and design theory that comprises every organization [58]. Therefore, these first cycle codes were deduced from the organizational structure and design theory. Hence, in line with Blumer [73], they benefit from the focus and guidance in the data analysis and provide a suggested direction for pattern identification. However, the data analysis at this stage was not limited by the first cycle codes, and no new codes emerged from the data.

The next step involved subcoding the data to enrich and provide details on the first cycle codes [66]. Explicitly, this step aimed to identify challenges and coping mechanisms, followed by identifying unique patterns among them and sorting the patterns into themes. Initially, a large number of challenges and coping mechanisms were identified and coded into second cycle codes within each of the core dimensions (ranging from 25-50 per core dimension). The second cycle codes were then reviewed, including re-labeling when necessary and removing overlaps. Also, the second cycle codes were eliminated if they did not correspond to the coordination of digital transformation, thus the purpose of this study. The next stage consisted of the identification and sorting of patterns. During the pattern sorting stage, themes emerged within each core dimension. Altogether, 2-3 themes were present for each core dimension that could enable presenting the data in a descriptive narrative. By this point, the drafts of themes and second cycle codes were repeatedly discussed among all authors, and appropriate adjustments were made. Also, second cycle codes and theme meanings, differences, and similarities were scrutinized by two authors to ensure coherence and validity. 
The findings were presented and discussed with the case company on two occasions (first with a key representative, second with the global team) to validate the accuracy of the contextual description, themes, and challenges and coping mechanisms. Moreover, key findings from the literature were compared with the collected empirical data [69], and conclusions were drawn. Emphasis was put on creating a detailed description of the challenges and coping mechanisms to increase potential transferability [66].

\section{Results}

In the case company, an organizational structure was created specifically to coordinate digital transformation in the IMN. This structure consisted of a global team, local teams at each of the 14 factories in the IMN, a companywide digital idea-sharing platform, and two forums (experience-sharing and standardization).

The creation of the new organizational structure started in 2018, and the global team was launched and has since been in charge of coordination, governance, and synchronization of the IMN regarding the digital transformation. In the case company, digital transformation is described as a continuous journey without an end date toward achieving smart and connected manufacturing in the IMN. This broad vision has been broken down into overall technology goals (e.g., autonomous control of manufacturing, data collection), ways of working and principles for digital transformation, and an overall roadmap covering how the digital transformation goals could be achieved. All of which have been established by the global team and communicated to the IMN in communication campaigns. Specifically, the global team's responsibility included creating an alignment within the IMN regarding what digital transformation entails. They established ways of working and principles for digital transformation, such as how the coordination of the IMN could be actualized with the help of an idea-sharing platform, experience-sharing, and standardization forums. The global team formed an overall strategy and a roadmap for the IMN that covered possible steps toward digital transformation. Moreover, a digital transformation self-evaluation tool was created, which the factories should use to make local factory roadmaps. Even though the global team set the principles regarding digital transformation, the factories and the local teams have the autonomy to adjust their digitalization activities to the factory vision and needs.

As part of the responsibility for creating an organizational structure to coordinate the digital transformation in the IMN, the global team guided the establishment of the local teams. The local teams performed digitalization activities in line with the digital transformation at their factories in the IMN. Employees at factories could appoint themselves to belong to the local team, meaning local team creation was volunteer-based. These members therefore had a genuine interest in exploring digital technologies and aligning their digitalization activities with the actual issues at the factory. However, the global team provided guidelines for team creation, including having approximately seven people and what type of competence to take in, e.g., maintenance, IT, logistics, and operations. The local teams also had dedicated time funded by their factories on digitalization activities and were connected to a factory sponsor group to support funding and provide high-level direction. Other guidelines addressed the ways of working, such as mandatory collaboration with manufacturing, engineering, and maintenance at the factories and that all local teams should have a leader. Moreover, the local teams were responsible during the testing phase (e.g., pilots); thereafter, the department took over the scale-up, but with support from the local team.

The global team set up a platform and two forums to ensure the synchronization of activities between factories and to facilitate coordination in the IMN regarding the digital transformation on three levels: (1) a digital idea-sharing platform where every local team can post an idea or an ongoing digitalization project. The intent was to increase the visibility and transparency of digitalization activities in the IMN and create a sense of community. The posted ideas or initiatives followed a standardized maturity process. (2) The digitalization ideas shared on the platform were extracted by the global team members for discussion to 
the experience-sharing forum; participation here consists of local team leaders, manufacturing engineering managers from each factory, and several global team members. (3) A standardization forum with two functions. The local teams could apply for global funding dedicated to digital transformation for the ideas shared in the idea-sharing platform and experience-sharing forum. Alternatively, the results from conducted digitalization activities were intended for standardization for the entire IMN. The participants in this forum were global and local factory managers and global team members.

The following headlines describe and exemplify the challenges of coordinating digital transformation in IMNs and the coping mechanisms to overcome these challenges from the core dimensions of differentiation, integration, centralization, and formalization.

\subsection{Differentiation}

The factories in the examined case differ in the number of employees working with digitalization in the local team. In general, the local team members only had a limited percentage of their working time available for digitalization, as they had several other duties in their regular work roles. The available time per resource, the number of resources, and functions involved in the local team varied between the factories depending on the number of employees at the factory. In one factory, the local team members worked fulltime with digitalization. Hence, there were different approaches to digital transformation in each factory in the IMN regarding local team activities, where some of the factories performed more activities than others, and as much as possible was to be performed with as few resources as possible. This also occurred at larger factories with enough resources. Therefore, the global team's expectations of the volume of activities and how each local team approaches the assignment differed among the factories.

However, the limited number of resources and how the local teams approached their responsibility caused coordination challenges for the global team. For instance, there was a need to understand the prerequisites of each factory when providing support and guidance, a task where a self-evaluation tool could be of aid. The global team assisted factories in the IMN in performing the self-evaluation and creating a roadmap supporting digitalization activities. By doing so, the global team gained insight into the context and prerequisites of the factories and their long-term goals. This could be beneficial in the coordination of digital transformation between factories, as interconnections could be identified.

Despite establishing local teams at each factory, there were misalignments between the established global organizational structure and the local factory management team, where limited steps were taken to align the factories' strategies with digital transformation. This means that the organizational structure on the local level had not been adjusted to fit the digital transformation, which led to a lack of pull from local factory management on the local team's activities, as exemplified by the following statement:

"Because if the site leadership doesn't really take ownership of this [the digital transformation], it's not gonna get done." (global team member 1)

Several possible coping mechanisms have been suggested, e.g., the importance of local factory management participation during self-evaluation to establish insight into the digital transformation in the IMN, understanding its importance, benefits, and gaining information. This can also connect the local factory strategy to the company's digital transformation strategy and use the local team's activities to attain the goals. Hence, this was a method for the global team to coordinate the digital transformation on even more local levels. Moreover, establishing local factory management ownership and pull could promote the local factory management to pose demands on local teams and create interest regarding their results, which were missing and had a discouraging effect on the local teams' momentum.

\subsection{Integration}

Even though the factories within the IMN were diverse, for example, regarding products, volumes, number of employees, and automatization, the teams within the digital 
transformation organizational structure depended on each other. This dependence could, for instance, concern keeping track of the progress in one local team to copy the solution in other factories. The responsibility for coordinating the digital transformation in the IMN was divided between the global team members; however, the global team members also realized the responsibility informally: for instance, if a local team requested support and guidance from a global team member depending on the required competence or expertise in the current digitalization activity.

Because some of the global team members had a dual role and were also local team members or leaders, they could facilitate a 'two-way communication' and better understand the needs and prerequisites of the local teams and factories and provide support and guidance. However, the local team member's views on the digital transformation could be limited by the needs and current state of their local factories, thereby risk restricting the ability to identify interconnections between the 'own' local team and the rest of the local teams in the IMN. Hence, a significant challenge to overcome was seeing the needs of the entire IMN rather than the needs of one factory and its current state regarding the digital transformation. The self-evaluation tool was estimated to mitigate the uncertainty of what needs to be coordinated in the IMN and functions as a guide for the global team to identify commonalities in local team initiatives.

Moreover, the global team created the idea-sharing platform and experience-sharing forum to increase the coordination of digital transformation in the IMN. These two tools benefited the coordination of digital transformation in IMN by promoting new collaborations and establishing new interfaces between the factories, as expressed below:

"I really feel like the global collaboration has advanced by having this structure we have now. Before this, I didn't have any contact with the other sites. I suppose that we worked pretty differently, and not much transparency existed. Now we don't work completely alone, and perhaps at least 30-40 percent of the work we do is transparent." (local team leader 1)

These tools were a way to share information, get new ideas, and receive support from the community pursuing similar digitalization activities. Even though this way of working has created some new interfaces and collaborations, several challenges still need to be overcome before the full potential is realized. Foremost, an initial challenge was to promote the value of the idea-sharing platform and encourage the local teams to post their ideas and initiatives and increase the momentum in utilizing the platform. By having both tools in place, this challenge had been mitigated to some degree. Specifically, the local team's efforts in their digitalization activities were valued because the posted ideas were highlighted and discussed in the experience-sharing forum, thus avoiding the risk of posting ideas that were later forgotten, which risked decreasing the utilization of the tools in the long run. The tools were complementary to each other.

Another challenge was balancing the trade-off between transparency that the tools provided in the IMN without creating an overwhelming amount of administrative work for the local teams and the global team that coordinates the tools. It takes time for the local teams to participate in all activities and remain updated on the occurrences in the IMN. The global team was aware of this but had not yet developed coping mechanisms for efficient ways of working with the tools.

Finally, the global team had set up the organizational structure for digital transformation in the IMN; however, the ambition was that the global team would inspire the local teams and the factories in their digital transformation rather than driving it, as exemplified in the following:

"We should be the movement leaders and inspire the organizations in this [digital transformation]" (global team member 2)

Hence, local ownership of the digital transformation was strived for in the long run. A part of this effort was that the local teams took ownership of the experience-sharing forum. The latest adjustment in running this forum was that the local teams take turns creating the agenda, still with the support from the global team, which could benefit the relevance of the conducted discussions. Therefore, a challenge was to balance the trade-off 
between local ownership and global overview. The global team needs a holistic overview of the digital transformation, as this facilitates coordination throughout the IMN, and this forum is one way to gain it. Nevertheless, several global team members also viewed it as vital that the local teams take ownership of the digital transformation to avoid top-down initiatives from the global team.

\subsection{Centralization}

The case company viewed digital transformation as a long-term journey without an end date. Support from top management had been attained partly because the digital transformation was initiated when both global managers and top management realized the need to address this and began to take steps in this direction, for instance, by setting up the local teams in each factory:

"And this is strongly supported by our [top] management. And it's not easy to tell the factory manager in a factory focusing on production that we need six people to be dedicated to some activities one day per week, with no added value immediately, just to prepare for the future." (global team member 3)

However, the global team considered that maintaining support from top management was more challenging than gaining it in the first place. A challenge here was to entrench an understanding in the top management that digital transformation of the IMN was a long-term transformation of the company. This company had a Lean culture, which complicated the top management's engagement, as exemplified:

"Lean means, you know, smart and also cheap, cheap in not only money but also the effort people need to spend. There could be voices that we shouldn't spend any money and time on this type of investment because we have bigger firefighting." (local team member 1)

Hence, there was a need for the global team to establish communication channels with top management and showcase the efforts made toward digital transformation in the IMN. For instance, showing the digital transformation's results and progress over time justified the investments of time and resources.

The findings also indicate that it was challenging to balance between starting small and only including the operations in the organizational structure for digital transformation or including other functions in the IMN, as exemplified in the following:

"And I really want to have end-to-end, everybody, purchasing, supplier, and then customers and sales. But right now, we [operations] need to learn, so we can show the benefits, and then we can invite them to come along." (global team member 1)

Even though other functions in the IMN were working toward their own digital transformation, the efforts were, thus far, not coordinated between them and operations. As exemplified in the above quote, the case company's choice to include only operations in the digital transformation was a deliberate decision; however, that meant risking embedding suboptimizations in the long run by excluding interdependent functions. To eventually broaden the scope and include the other functions, a challenge emerged of increasing visibility of the digital transformation beyond operations and communicating with the rest of the functions, thus increasing the coordination needed in the IMN.

\subsection{Formalization}

The global team had created the overall strategy and principles for digital transformation in the IMN. Such principles included creating a local team according to the global team's guidelines, e.g., suggested competence areas to include regularity in meetings, usage of the idea-sharing platform, and the experience-sharing forum. Hence, the implementation of principles was the responsibility of the local factories. Other principles were more formalized, e.g., applying for funding in the standardization forum, standardizing solutions in the standardization forum, assessing the maturity of the developed ideas posted in the idea-sharing platform, and the self-assessment and roadmap creation procedure.

One of the principles orchestrated by the global team was to have a bottom-up approach, meaning that the local teams take ownership of the digital transformation, and the global team guides the process depending on the needs of their factories. The local 
teams should have time to explore and understand their factory's needs for digitalization. However, the challenge was for the global team to balance the governance of the local teams while avoiding hierarchy and an abundance of rules and standard procedures that would risk choking the excitement of participating, as expressed in the quote below:

"So we don't want to command and say, no, you [the local teams] need to get to this level by this point. Of course, when they come to us, we try to give some support and ideas, but we are not trying to dictate how fast they should be moving." (global team member 1)

This challenge possibly stemmed from the diverging cultures of the factories within the IMN, where some local teams were expecting clear rules and directives and others were content with the current freedom from rules. Moreover, finding an appropriate level of formalization could aid the local teams in their avoidance of performing digitalization activities without rooting the activity in an actual factory need, e.g., exploring technologies without understanding the factory's requirements and processes and risk adding problems to the existing processes. The global team suggested one way to approach this challenge by involving Lean specialists in the local teams to highlight overlooked aspects and provide a continuous improvement mentality.

Clarifying formalization of the local team's responsibilities could also be beneficial for establishing deliverables, expectations, and role descriptions. Coping with this challenge could lead to adjustments of the ways of working on local teams. Having deliverables for digitalization in place could provide direction to the local teams and could facilitate gaining support from local factory management.

The findings also indicate a challenge regarding the lack of the global team's previous experience and expertise concerning how to initiate and conduct a digital transformation and ensure its coordination in the IMN. There was no way of knowing how to approach the digital transformation for it to be successful, as described below:

"I think it was interesting to see that a lot of people are interested, there is a lot of energy, but there's also a lot of competence that we [the global team] need to gain, because it's not that we're bringing in people that did this before, so we are learning as we are going." (global team member 2)

Compared to previous significant company changes, the digital transformation was viewed as more complex, required diverse competencies, and contained more uncertainties, especially concerning what to coordinate and how to structure an organization that facilitates the coordination of digital transformation. The global team thus designed the organizational structure for digital transformation to leave intentional room for evolvement and adjustment, such as the hand-over of the experience-sharing forum responsibility to the local teams, described previously. One of the uncertainties that posed a challenge for the global team is a lack of a detailed plan or a holistic roadmap for the team itself that contains future focus areas, as exemplified in the following:

"There is a vision [for digital transformation], but the vision is on a general level, but I believe if every sub-area had a more detailed map over what will happen in the future, to be able to know what to focus on and where there could be potential issues. So we [the global team] could have a united map over what will happen and not only in my area but also in the surrounding areas." (global team member 4)

Having such a roadmap could mitigate the risk of having person-dependent responsibilities in the global team, where the loss of a specific competence could pose a challenge.

However, there were no role descriptions in general for the global team, which was a challenge. Similarly, some members possessed dual roles and were also local team members or leaders who lacked a role description, which caused uncertainty, as exemplified in the following:

"The role is not super clear. It can be to bring in my previous experiences and the experiences I gain by being part in this [local team] also into this forum [global team], I guess." (local team leader 2)

Hence, how the dual role members could be utilized and be beneficial in the long run were not specified, leading to different views over what they were supposed to achieve. Nevertheless, such roles have the potential to increase coordination between the global and local teams. 


\subsection{Summary of Results}

Figure 2 provides an overview and summarizes the case study findings of the 15 experienced challenges and the 11 coping mechanisms identified in the case company when coordinating the digital transformation in their IMN. The coping mechanisms were both actual and possible in a future setting.

\begin{tabular}{|c|c|c|}
\hline $\begin{array}{l}\text { Challenges with the } \\
\text { coordination of digital } \\
\text { transformation in IMNs }\end{array}$ & & $\begin{array}{l}\text { Coping mechanisms for the } \\
\text { coordination of digital } \\
\text { transformation in IMNs }\end{array}$ \\
\hline $\begin{array}{l}\text { - Limited number of resources for digital } \\
\text { transformation } \\
\text { - Different approaches to digital } \\
\text { transformation in each factory in the } \\
\text { IMN } \\
\text { - The factories' organizational structure } \\
\text { not adapted to the digital transformation }\end{array}$ & Differentiation & $\begin{array}{l}\text { - Create understanding that the factories } \\
\text { in the IMN have different prerequisites } \\
\text { - Use the self-evaluation and formulation } \\
\text { of the roadmap as a tool to on-board } \\
\text { local management } \\
\text { - Establish pull from local management to } \\
\text { maintain digitalization momentum }\end{array}$ \\
\hline $\begin{array}{l}\text { - Difficult to view the digital } \\
\text { transformation from an IMN } \\
\text { perspective } \\
\text { - Difficult to promote the value of sharing } \\
\text { digitalization ideas } \\
\text { - Difficult to balance the trade-off } \\
\text { between transparency and } \\
\text { administrative work } \\
\text { - Difficult to balance the trade-off } \\
\text { between local ownership and global } \\
\text { overview }\end{array}$ & Integration & $\begin{array}{l}\text { - Gain global level understanding of the } \\
\text { needs and current state of the factories } \\
\text { in the IMN to provide accurate support } \\
\text { and guidance } \\
\text { - Use the self-evaluation to mitigate the } \\
\text { coordination uncertainty } \\
\text { - Establish a platform where factories in } \\
\text { the IMN can post ideas together with a } \\
\text { forum where they can be discussed }\end{array}$ \\
\hline $\begin{array}{l}\text { - Difficult to establish an understanding of } \\
\text { the long-term benefits of digital } \\
\text { transformation in the IMN } \\
\text { - Difficult to maintain support from top } \\
\text { management in the IMN } \\
\text { - Difficult to balance the trade-off of } \\
\text { starting small or include everyone in the } \\
\text { IMN }\end{array}$ & Centralization & $\begin{array}{l}\text { - Establish communication channels from } \\
\text { global level to top management to show } \\
\text { results, justify resources and } \\
\text { demonstrate progress in the IMN } \\
\text { - Promote digital transformation within, } \\
\text { and increase awareness of it beyond, } \\
\text { operations in the IMN }\end{array}$ \\
\hline $\begin{array}{l}\text { - Different needs of global governance } \\
\text { and desired degree of freedom from the } \\
\text { factories in the IMN } \\
\text { - Difficult to ensure the potential global } \\
\text { synergy effect yet allowing local } \\
\text { exploration } \\
\text { - Lack of global level competence of how } \\
\text { to conduct the digital transformation } \\
\text { in the IMN } \\
\text { - Lack of long-term direction on global } \\
\text { level in the IMN } \\
\text { - Differing views on roles and } \\
\text { responsibilities within the organization } \\
\text { for digital transformation in the IMN }\end{array}$ & Formalization & $\begin{array}{l}\text { - Set clear local deliverables that guides } \\
\text { the distribution of resources } \\
\text { - Determine the long-term global level } \\
\text { activities and way of working } \\
\text { - Create descriptions of roles, } \\
\text { responsibilities and expectations on } \\
\text { local and global levels in the IMN }\end{array}$ \\
\hline
\end{tabular}

Figure 2. Summary of the case study findings of challenges with the coordination of digital transformation in IMNs and the coping mechanisms to overcome these based on the core dimensions of organizational structure and design theory.

\section{Discussion and Implications}

Drawing on organizational structure and design theory, the case study findings were analyzed based on the core dimensions of differentiation, integration, centralization, and formalization. This approach provided a thorough contextual description of the case and 
benefited the understanding of the challenges with the coordination of digital transformation in IMNs and the coping mechanisms to overcome these. Thus, this study also bridges the gap in previous research that has focused on either the digital transformation of individual factories or on the technology perspective.

Specifically, the examined case has similarities with previous research concerning the construction of local- and global-level specialized cross-functional teams $[17,27,59,62]$. However, combining research on digital transformation with the coordination of IMN guided the development of some coping mechanisms, explicitly, the description of roles [36] and responsibilities [39]. Defining the roles and responsibilities is sought after at both the local and global levels. Arguably, formalizing this is a balancing act; doing it too quickly and unintentionally risks restricting the roles and responsibilities, affecting any possible needed future adjustments. Also, as found in the case analysis, which is perhaps unique to digital transformations, expectations of the teams, both on the local and global levels, need to be described.

It seems that finding a balance with a 'right' amount of top-down digital transformation formalization without suffocating digitalization at the local level is a significant challenge in an IMN. Because the factories have different prerequisites, resources, and cultures, the latter primarily affects expectations regarding the amount and rigor of formalization. Moreover, as exemplified by a global team member, there is no complete answer for how to successfully undergo a digital transformation because every company is still in progress and thus does not possess sufficient competence and expertise on how to proceed. Moreover, every company faces significant challenges $[54,55]$ that evolve over time [55]. Hence, there is no one to look to for guidance regarding the deployment of correct coping mechanisms. Therefore, the formalization in the examined case is constantly revised and adjusted depending on the needs of the IMN and the gained lessons learned by the global team. Uncertainty is high regarding what needs to be coordinated, how it could be coordinated, and what kind of formalization needs to be developed to facilitate the coordination. So, finding a balance within formalization is necessary to avoid solely local technology adaptations and a loss of the synergy effect gained by coordinating the digital transformation throughout the IMN. Nevertheless, digital technology implementation has been shown to contribute to enhancing production processes [50,51], which has the potential to improve sustainability (i.e., society and economy) [52,53]. Arguably, local digital technology adaptations can benefit other areas of production than the process itself. However, it is necessary to formalize the coordination to realize synergy effects and ensure that the digital technology implementation's positive effects on the sustainability pillars can be diffused within the IMN.

In the examined case, the self-evaluation tool was used to assess the factory prerequisites. However, it is not the self-evaluation tool itself that is of interest in this paper, but rather how it is used for coordination purposes. The findings show that the global team intends to use the self-evaluation tool as a coping mechanism in the dimensions of differentiation and integration. Because the global team participates in local assessments, understanding each factory's prerequisites and needs can be gained. Also, this can help the global team understand the current status of digitalization in each factory, which is an essential prerequisite for coordination and can aid the global team in providing accurate support and guidance [38]. Hence, the self-evaluation can benefit the global team in creating an overview of the digital transformation in the IMN. This, in turn, can aid the synchronization of digitalization activities between factories and create a long-term agenda for the global team that mitigates coordination uncertainty. The effects can thus also be tracked to the formalization dimension.

Even though an organizational structure is created for a digital transformation in an IMN, it is mainly contained to the global level, with the exemption of the local teams' establishment. Hence, there are coping mechanisms yet to be developed. The self-evaluation is intended to entrench the digital transformation into the local factory management and establish local ownership, partly because the global team can communicate the digital 
transformation directly to them. This can be viewed as informal coordination with the possibility of shared organizational culture and objectives in the IMN [36]. Local factory management's lack of attention regarding digital transformation can otherwise challenge gaining resources for the local teams. The misalignment of local organizational structure to the digital transformation also requires local factory management recognition, because, for the digital transformation to be successful, a transformation of the organizational structure is also needed [4]. One challenge for the coordination of digital transformation is establishing local ownership in factories that embraces the importance of digital transformation and values the efforts of local teams. Therefore, digital transformation risks losing momentum in the long run if global team efforts are not matched by corresponding changes in the factories' organizations.

Integration has benefited from the recently developed organizational structure for digital transformation because of the focus on increasing coordination throughout the IMN. Likewise, the organizational structure for digital transformation has benefited the transparency of digitalization ideas, initiatives, and projects. IMNs have interdependencies that need to be identified [3,4], and factories need to be aware and partake in the technology, process, product development, updates, and improvements occurring at each factory $[33,38]$. The structure in the examined case promotes these aspects of coordination. A primary coping mechanism is the complementary idea-sharing platform and forums (experiencesharing and standardization) created for coordination purposes, which has increased collaboration between local teams and, thus, the factories. Nevertheless, some coordination challenges still lack definite coping mechanisms, such as finding the balance between local ownership in the experience-sharing forum while retaining an overview and involvement of the global team. This demonstrates that collaboration does not happen organically and needs a detailed plan [26], meaning that formalization is required to achieve coordination.

Overall digital transformation governance is attributed to the global level in the examined case, which is in line with the formal management structures necessary for coordination, which should cover the decision-making rights [39,59], responsibilities [39], and autonomy to perform the assigned tasks [59]. Maintaining support from top management proved to be challenging, as it requires communication and reinforcement regarding the investments made into the digital transformation. Further, it requires entrenching an understanding in top management to view the digital transformation as a long-term investment for the future of the IMN where immediate value might not be apparent. The findings are supported by previous research that enforces the long-term perspective, which can benefit the progress of digital transformation and ease coping with mistakes [27]. Likewise, it is necessary to attain top management conviction, involvement, and support [17] and close collaboration [33] across the IMN. The coordination by the global team is thus performed to attain an overview of the local digitalization initiatives and redirect the information to top management to maintain the support of the digital transformation.

Interestingly, because the digital transformation is confined to the operations side of the IMN, with limited coordination to the whole company, this might lead to suboptimizations in the future. Some preventative coping mechanisms have been deployed, yet how to best cope with this challenge remains unexplored.

\section{Theoretical and Managerial Implications}

This study contributes to the growing body of literature on the coordination of IMNs and, more specifically, on coordinating digital transformation in IMNs. By adopting an organizational view, challenges and ways to cope with these challenges have been examined from four different dimensions, thus promoting the understanding of the coordination of digital transformation in IMNs, its complexities, and its uncertainties. The findings contribute to theory in two main ways.

First, a thorough description of the case company's organizational structure was provided, and its reasoning and intent for digital transformation in the IMN were explained, increasing the understanding of the organizational perspective, which has gained limited 
attention in previous research and is considered to be in its infancy [4]. Even though there seems to be a consensus regarding the importance of the organizational structure when it comes to digital transformation in previous research $[4,14,17,25]$, most of the current research focuses on digital technology enablers [24]. This study adds to the growing body of research covering digital transformation by first describing the created organizational structure for digital transformation, but more importantly, in contrast to previous research, focuses on the coordination aspect. This leads to the second contribution to theory; 15 challenges and 11 actual or possible coping mechanisms for the coordination of digital transformation in an IMN were identified. These are, in summary, presented in Figure 2 and connected to the core dimensions of differentiation, integration, centralization, and formalization. These challenges and coping mechanisms are also thoroughly described and exemplified with empirical data. The findings add to previous work, e.g., [17], by focusing on the IMN perspective as previous research has mainly adopted a factory perspective or focused on the implications of digital technologies on value chains, e.g., [20,23].

In addition to the theoretical contribution, the paper also provides valuable managerial implications relevant for managers who are active in coordinating digital transformation in IMNs. Additionally, local factory management can utilize the findings to understand how digitalization activities at the local factory level contribute to or fit the digital transformation of the IMN. First, Figure 2 can be used as a checklist for managers working with coordinating digital transformation in IMNs. The case findings demonstrate the challenges that occur during a digital transformation, how they evolve, and the coping mechanisms used to mitigate them. The findings in this study can thus be valuable for managers when investigating the way forward with the digital transformation that goes beyond digitalization and digital technology exploration.

Second, Figure 2 can be used as a tool to facilitate discussion among local factories and global teams or managers. This is because, as the findings show, the factories in an IMN can have different prerequisites and needs, therefore it is of importance on the global level to understand those to create an organizational structure where coordination is possible. Local factory management needs to align local strategies with the digital transformation and investigate whether local adaptations to organizational structures are needed. Third, by highlighting the organizational perspective, the findings support managers in developing organizational structures for digital transformation in their IMNs while avoiding the challenges faced by the case company. Specifically, the essential finding in this paper is that during the creation of its organizational structure, the case company had the coordination and synergy of the IMN in its center. Moreover, it is worth pointing out that the organizational structure in the case study was not static; it was adapted and adjusted according to the needs for coordination arising in the IMN, which is valuable input for global managers.

\section{Conclusions}

This paper provides an increased understanding of the coordination of digital transformation in IMNs. Explicitly, by using the core dimensions of the organizational structure and design theory, this paper yields a thorough description of the context of the case company and how the coordination of digital transformation is approached. This case study's primary results are the identified 15 challenges and 11 coping mechanisms for coordination of digital transformation in an IMN. These challenges and coping mechanisms are framed within the case context to benefit their understanding.

One of the main findings is that a coordination-oriented organizational structure is necessary for digital transformation in an IMN. Expressly, establishing cross-functional teams on both global and local levels is confirmed by this study. By comparing digital transformation and coordination research and placing them within the organizational structure and design theory view, this study provides complementary perspectives and concrete examples of how such an organization can be constructed. Most importantly, this study indicates that solely establishing teams on different levels within an IMN is insufficient 
and should be combined with deliberately establishing how digital transformation can be coordinated in IMNs. For instance, a primary coping mechanism is the reciprocality of a platform where local factory digitalization ideas can be shared within the IMN and also discussed in a forum. It is also important to point out that such means of coordinating the digital transformation in the IMN are related to increased collaboration and transparency across factories in an IMN.

Although it is difficult to specify the most crucial challenges and coping mechanisms, the challenge of the local factories' organizational structure's lack of adaptation to the digital transformation attains attention as this poses consequences for coordination of digital transformation across the IMN. Even though the case study demonstrates an organizational structure for digital transformation, it is mostly contained on the global level of the IMN, and local factory ownership of digital transformation is challenging to establish. Also, uncertainty within the formalization dimension needs particular attention. This dimension has the most amount of identified challenges and the least amount of clearly defined coping mechanisms. As demonstrated by the case company, formalization is constantly revised and adjusted based on the needs of the IMN and the continuously gained experience by the global team. This indicates that this dimension is especially exposed to the changes caused by digital transformation and consequently leads to the difficulty of identifying the corresponding formalization that needs to be developed to facilitate coordination across the IMN.

\section{Limitations and Outlook}

This paper is limited to the organizational perspective of the case company. The data sample includes functions typically not represented in operations management (OM) literature, such as human resources (HR), demonstrating that digital transformation requires insights from multiple functions through the IMN. However, the organizational perspective was confined to the IMN level and mostly global managers, with a limited number of local factory respondents. One of the findings in this case study was that the organizational structure at the factory level was not adapted to the digital transformation. Within this case study, goals, ways of working and principles, and an overall roadmap for digital transformation were defined at the global level by the global team. Nevertheless, how local factories translate and comply with the global digital transformation direction and make possible adjustments to their organizational structures are unexplored. Moreover, how this affects IMN coordination is a possible way forward in future research.

Although this research has generated a new understanding regarding challenges and coping mechanisms for coordination of digital transformation in IMNs, future work should include measurement of sustainability aspects to measure the value of the identified coping mechanisms. Measurement could be done in several areas, e.g., economical (e.g., quality improvements, development time), environmental (e.g., power consumption, transportation), and human/social (e.g., employee satisfaction, communication, sick leave). By collecting quantitative data, the value from each identified coping mechanism can be elaborated and thereby add value to the results.

Lastly, this paper presented detailed insights into the challenges and coping mechanisms of coordinating the digital transformation in an IMN. This study adds to previous research, e.g., [17], by focusing on the IMN perspective. However, the limitations of the study must be considered. This case study has been conducted at one company in the heavy vehicle industry, thus limiting the generalization of the context studied. Therefore, a natural proposal for further research is to examine challenges and coping mechanisms for coordination of digital transformation in IMNs in other types of industries and/or involve more case companies. This would increase the validity of the results. Hence, more research is needed to compare multiple cases, preferably within different industries, which could provide more insight into contextual factors that affect challenges and coping mechanisms. Most importantly, it would strengthen the generalizability of the findings. Empirical research is generally limited in the OM research field, especially in global production; hence, 
multiple case studies could provide several perspectives that could benefit managers who coordinate their IMNs.

Author Contributions: Conceptualization, V.B.; investigation, V.B.; writing-original draft preparation, V.B.; writing-review and editing, V.B., A.G., M.A. and J.B.; visualization, V.B.; supervision, A.G., M.A. and J.B.; funding acquisition, A.G., M.A., V.B. and J.B. All authors have read and agreed to the published version of the manuscript.

Funding: This research was funded by Strategic Vehicle Research and Innovation (FFI) grant no. 2020-02991.

Institutional Review Board Statement: Not applicable.

Informed Consent Statement: Not applicable.

Data Availability Statement: Not applicable.

Acknowledgments: The authors gratefully acknowledge the participation and contribution of the case company. The research was conducted as part of the XPRES framework at Mälardalen University.

Conflicts of Interest: The authors declare no conflict of interest.

\section{References}

1. Barlett, C.A.; Ghoshal, S. Managing across Borders: The Transnational Solution, 2nd ed.; Harvard Business School Press: Boston, MA, USA, 1998.

2. Vereecke, A.; Van Dierdonck, R.; De Meyer, A. A typology of plants in global manufacturing networks. Manag. Sci. 2006, 52, 1737-1750. [CrossRef]

3. Cuenca, L.; Boza, A.; Alemany, M.M.E.; Trienekens, J.J.M. Structural elements of coordination mechanisms in collaborative planning processes and their assessment through maturity models: Application to a ceramic tile company. Comput. Ind. 2013, 64, 898-911. [CrossRef]

4. Horváth, D.; Szabó, R.Z. Driving forces and barriers of Industry 4.0: Do multinational and small and medium-sized companies have equal opportunities? Technol. Forecast. Soc. Chang. 2019, 146, 119-132. [CrossRef]

5. Ferdows, K. Keeping up with growing complexity of managing global operations. Int. J. Oper. Prod. Manag. 2018, 38, 390-402. [CrossRef]

6. Siachou, E.; Vrontis, D.; Trichina, E. Can traditional organizations be digitally transformed by themselves? The moderating role of absorptive capacity and strategic interdependence. J. Bus. Res. 2021, 124, 408-421. [CrossRef]

7. Kane, G.C.; Nguyen Phillips, A.; Copulsky, J.R.; Andrus, G.R. The Technology Fallacy, 1st ed.; MIT Press: Cambridge, MA, USA, 2019. [CrossRef]

8. Liere-Netheler, K.; Packmohr, S.; Vogelsang, K. Drivers of digital transformation in manufacturing. In Proceedings of the 51st Hawaii International Conference on System Sciences (HICSS 2018), Waikoloa, HI, USA, 3-6 January 2018; Shidler College of Business: Honolulu, HI, USA, 2018. [CrossRef]

9. Jorge-Vázquez, J.; Chivite-Cebolla, M.P.; Salinas-Ramos, F. The digitalization of the european agri-food cooperative sector. Determining factors to embrace information and communication technologies. Agriculture 2021, 11, 514. [CrossRef]

10. Tavares-Lehmann, A.T.; Varum, C. Industry 4.0 and Sustainability: A Bibliometric Literature Review. Sustainability 2021, 13, 3493. [CrossRef]

11. Garetti, M.; Taisch, M. Sustainable manufacturing: Trends and research challenges. Prod. Plan. Control 2012, 23, 83-104. [CrossRef]

12. Majchrzak, A.; Markus, M.L.; Wareham, J. Designing for digital transformation: Lessons for information systems research from the study of ICT and societal challenges. MIS Q. Manag. Inf. Syst. 2016, 40, 267-277. [CrossRef]

13. Massaro, M. Digital transformation in the healthcare sector through blockchain technology. Insights from academic research and business developments. Technovation 2021, 1-12. [CrossRef]

14. Verhoef, P.C.; Broekhuizen, T.; Bart, Y.; Bhattacharya, A.; Qi Dong, J.; Fabian, N.; Haenlein, M. Digital transformation: A multidisciplinary reflection and research agenda. J. Bus. Res. 2021, 122, 889-901. [CrossRef]

15. Loonam, J.; Eaves, S.; Kumar, V.; Parry, G. Towards digital transformation: Lessons learned from traditional organizations. Strateg. Chang. 2018, 27, 101-109. [CrossRef]

16. Hallstedt, S.I.; Isaksson, O.; Öhrwall Rönnbäck, A. The need for new product development capabilities from digitalization, sustainability, and servitization trends. Sustainability 2020, 12, 10222. [CrossRef]

17. Steiber, A.; Alänge, S.; Ghosh, S.; Goncalves, D. Digital transformation of industrial firms: An innovation diffusion perspective. Eur. J. Innov. Manag. 2020, 24, 799-819. [CrossRef]

18. Deflorin, P.; Scherrer, M.; Schillo, K. The influence of IIoT on manufacturing network coordination. J. Manuf. Technol. Manag. 2021, 32, 1144-1166. [CrossRef]

19. Hess, T.; Benlian, A.; Matt, C.; Wiesböck, F. Options for formulating a digital transformation strategy. MIS Q. Exec. 2016, 15, 123-139. [CrossRef]

20. Strange, R.; Zucchella, A. Industry 4.0, global value chains and international business. Multinatl. Bus. Rev. 2017, 25, 174-184. [CrossRef] 
21. Schmidt, M.C.; Veile, J.W.; Müller, J.M.; Voigt, K.I. Ecosystems 40: Redesigning global value chains. Int. J. Logist. Manag. 2021, 32, 1124-1149. [CrossRef]

22. Alcácer, J.; Cantwell, J.; Piscitello, L. Internationalization in the information age: A new era for places, firms, and international business networks? J. Int. Bus. Stud. 2016, 47, 499-512. [CrossRef]

23. Ben-Daya, M.; Hassini, E.; Bahroun, Z. Internet of things and supply chain management: A literature review. Int. J. Prod. Res. 2019, 57, 4719-4742. [CrossRef]

24. Büyüközkan, G.; Göçer, F. Digital Supply Chain: Literature review and a proposed framework for future research. Comput. Ind. 2018, 97, 157-177. [CrossRef]

25. Hanelt, A.; Bohnsack, R.; Marz, D.; Antunes Marante, C. A Systematic Review of the Literature on Digital Transformation: Insights and Implications for Strategy and Organizational Change. J. Manag. Stud. 2021, 58, 1159-1197. [CrossRef]

26. Vial, G. Understanding digital transformation: A review and a research agenda. J. Strateg. Inf. Syst. 2021, 28, 13-66. [CrossRef]

27. Smith, P.; Beretta, M. The Gordian Knot of Practicing Digital Transformation: Coping with Emergent Paradoxes in Ambidextrous Organizing Structures. J. Prod. Innov. Manag. 2021, 38, 166-191. [CrossRef]

28. Bosman, L.; Hartman, N.; Sutherland, J. How manufacturing firm characteristics can influence decision making for investing in Industry 4.0 technologies. J. Manuf. Technol. Manag. 2020, 31, 1117-1141. [CrossRef]

29. Cheng, Y.; Chaudhuri, A.; Farooq, S. Interplant coordination, supply chain integration, and operational performance of a plant in a manufacturing network: A mediation analysis. Supply Chain Manag. Int. J. 2016, 21, 550-568. [CrossRef]

30. Cheng, Y.; Farooq, S. The role of plants in manufacturing networks: A revisit and extension. Int. J. Prod. Econ. 2018, 206, 15-32. [CrossRef]

31. Maritan, C.A.; Brush, T.H.; Karnani, A.G. Plant roles and decision autonomy in multinational plant networks. J. Oper. Manag. 2004, 22, 489-503. [CrossRef]

32. Shi, Y.; Gregory, M. International manufacturing networks-To develop global competitive capabilities. J. Oper. Manag. 1998, 16, 195-214. [CrossRef]

33. Rudberg, M.; West, M.B. Global operations strategy: Coordinating manufacturing networks. Int. J. Manag. Sci. 2008, 36, 91-106. [CrossRef]

34. Cheng, Y.; Farooq, S.; Johansen, J. Manufacturing network evolution: A manufacturing plant perspective. Int. J. Oper. Prod. Manag. 2011, 31, 1311-1331. [CrossRef]

35. Ferdows, K. Transfer of changing production know-how. Prod. Oper. Manag. 2006, 15, 1-9. [CrossRef]

36. Martinez, J.I.; Jarillo, J.C. The evolution of research on coordination mechanisms in multinational corporations. J. Int. Bus. Stud. 1989, 20, 489-514. [CrossRef]

37. Shi, Y. Internationalisation and evolution of manufacturing systems: Classic process models, new industrial issues, and academic challenges. Integr. Manuf. Syst. 2003, 14, 357-368. [CrossRef]

38. Granlund, A.; Rösiö, C.; Bruch, J.; Johansson, P.E. Lead factory operationalisation and challenges. Prod. Plan. Control 2019, 30, 96-111. [CrossRef]

39. Friedli, T.; Mundt, A.; Thomas, S. Strategic Management of Global Manufacturing Networks: Aligning Strategy, Configuration, and Coordination; Springer: Berlin, Germany, 2014.

40. Cheng, Y.; Johansen, J.; Hu, H. Exploring the interaction between R\&D and production in their globalisation. Int. J. Oper. Prod. Manag. 2015, 35, 782-816. [CrossRef]

41. Cheng, Y.; Johansen, J. Operations network development: Internationalisation and externalisation of value chain activities. Prod. Plan. Control 2014, 25, 1351-1369. [CrossRef]

42. Parida, V.; Sjödin, D.; Reim, W. Reviewing literature on digitalization, business model innovation, and sustainable industry: Past achievements and future promises. Sustainability 2019, 11,391. [CrossRef]

43. Gong, C.; Ribiere, V. Developing a unified definition of digital transformation. Technovation 2021, 102, 102217. [CrossRef]

44. Fitzgerald, M.; Kruschwitz, N.; Bonnet, D.; Welch, M. Embracing Digital Technology: A New Strategic Imperative. MIT Sloan Manag. Rev. 2013, 55, 1-12.

45. Oztemel, E.; Gursev, S. Literature review of Industry 4.0 and related technologies. J. Intell. Manuf. 2020, 31, 127-182. [CrossRef]

46. Newell, S.; Marabelli, M. Strategic opportunities (and challenges) of algorithmic decision-making: A call for action on the long-term societal effects of "datification". J. Strateg. Inf. Syst. 2015, 24, 3-14. [CrossRef]

47. Felsberger, A.; Reiner, G. Sustainable industry 4.0 in production and operations management: A systematic literature review. Sustainability 2020, 12, 7982. [CrossRef]

48. Gholami, H.; Abu, F.; Ke, J.; Lee, Y.; Karganroudi, S.S. Sustainable Manufacturing 4.0—Pathways and Practices. Sustainability 2021, 13, 13956. [CrossRef]

49. Enyoghasi, C.; Badurdeen, F. Industry 4.0 for sustainable manufacturing: Opportunities at the product, process, and system levels. Resour. Conserv. Recycl. 2021, 166, 1-14. [CrossRef]

50. Rajput, S.; Singh, S.P. Connecting circular economy and industry 4.0. Int. J. Inf. Manag. 2019, 49, 98-113. [CrossRef]

51. Rajput, S.; Singh, S.P. Industry 4.0—Challenges to implement circular economy. Benchmarking Int. J. 2021, 28, 1717-1739. [CrossRef]

52. MacArthur, E.; Waughray, D. Intelligent Assets: Unlocking the Circular Economy Potential; Ellen MacArthur Foundation: Cowes, UK, 2016. Available online: https://www.ellenmacarthurfoundation.org/assets/downloads/publications/ EllenMacArthurFoundation_Intelligent_Assets_080216.pdf (accessed on 22 January 2022). 
53. Blunck, E.; Werthmann, H. Industry 4.0-An opportunity to realize sustainable manufacturing and its potential for a circular economy. In Proceedings of the Dubrovnik International Economic Meeting (DIEM), Dubrovnik, Croatia, 12-14 October 2017; Volume 3, pp. 644-666.

54. Bleicher, J.; Stanley, H. Digitization as a catalyst for business model innovation a three-step approach to facilitating economic success. J. Bus. Manag. 2016, 4, 62-71.

55. Warner, K.S.R.; Wäger, M. Building dynamic capabilities for digital transformation: An ongoing process of strategic renewal. Long Range Plann. 2019, 52, 326-349. [CrossRef]

56. Singh, A.; Hess, T. How chief digital officers promote the digital transformation of their companies. MIS Q. Exec. 2017, 16, 1-17. [CrossRef]

57. Schumacher, A.; Erol, A.; Sihn, W. A maturity model for assessing Industry 4.0 readiness and maturity of manufacturing enterprises. Procedia CIRP 2016, 52, 161-166. [CrossRef]

58. Donaldson, L. Organizational Structure and Design. In Encyclopedia of Management Theory, 1st ed.; Kessler, E.H., Ed.; Sage Publications: Los Angeles, CA, USA, 2013; pp. 569-574.

59. Felin, T.; Powell, T.C. Designing organizations for dynamic capabilities. Calif. Manag. Rev. 2016, 58, 78-96. [CrossRef]

60. Barron, A.; Pereda, A. Exploring how firms' strategic political actions are organised to capture and share external information -The case of Alpha Plc. Long Range Plann. 2020, 53, 101931. [CrossRef]

61. Donaldson, L. The Contingency Theory of Organizations, 2nd ed.; SAGE Publications: Thousand Oaks, CA, USA, 2014. [CrossRef]

62. Perrow, C. The bureaucratic paradox: The efficient organization centralizes in order to decentralize. Organ. Dyn. 1977, 5, 3-14. [CrossRef]

63. Albers, S.; Wohlgezogen, F.; Zajac, E.J. Strategic alliance structures: An organizational design perspective. J. Manag. 2016, 42, 582-614. [CrossRef]

64. Foss, N.J.; Laursen, K.; Pedersen, T. Linking customer interaction and innovation: The mediating role of new organizational practices. Organ. Sci. 2011, 22, 980-999. [CrossRef]

65. Lawrence, P.R.; Lorsch, J.W. Differentiation and integration in complex organizations. Adm. Sci. Q. 1967, 12, 1-47. [CrossRef]

66. Miles, H.; Huberman, M. Qualitative Data Analysis: An Expanded Sourcebook, 2nd ed.; SAGE: Thousand Oaks, CA, USA, 1994.

67. Svahn, F.; Mathiassen, L.; Lindgren, R. Embracing digital innovation in incumbent firms: How Volvo Cars managed competing concerns. MIS Q. Manag. Inf. Syst. 2017, 41, 239-253. [CrossRef]

68. Voss, C.; Tsikriktsis, N.; Frohlich, M. Case research in operations management. Int. J. Oper. Prod. Manag. 2002, 22, 195-219. [CrossRef]

69. Eisenhardt, K.M. Building theories from case study research. Acad. Manag. Rev. 1989, 14, 532-550. [CrossRef]

70. Yin, R.K. Case Study Research—Design and Methods, 4th ed.; SAGE: Thousand Oaks, CA, USA, 2009.

71. Voss, C. Case research in Operations Management. In Researching Operations Management, 1st ed.; Karlsson, C., Ed.; Routledge: New York, NY, USA, 2009; pp. 162-195.

72. Patton, M.Q. Qualitative Research and Evaluation Methods, 3rd ed.; SAGE: London, UK, 2002.

73. Blumer, H. What Is Wrong with Social Theory? Sociol. Methods 1954, 19, 84-96. [CrossRef] 